\title{
Skeletal Muscles: Insight into Embryonic Development, Satellite Cells, Histology, Ultrastructure, Innervation, Contraction and Relaxation, Causes, Pathophysiology, and Treatment of Volumetric Muscle Injury.
}

\author{
Marwan T. M. Abofila1, Azab Elsayed Azab ${ }^{2 *}$, Amal M. A. Al Shebani' ${ }^{3}$, and Asmaa Najeeb Ali Absheenah ${ }^{3}$ \\ ${ }^{1}$ Department of Anatomy, Histology and Embryology, Faculty of Medicine, Sabratha University, Libya \\ ${ }^{2}$ Department of Physiology, Faculty of Medicine, Sabratha University, Libya \\ ${ }^{3}$ Department of Histology, Faculty of Medicine, Zawia University, Libya
}

Corresponding Author: Azab Elsayed Azab, Department of Physiology, Faculty of Medicine, Sabratha University, Sabratha Libya. Received date: April 03, 2021; Accepted date: April 19, 2021; Published date: April 23,2021

Citation: Marwan T. M. Abofila, Azab E. Azab and Asma N. Bshena (2021) Skeletal Muscles: Insight into Embryonic Development, Satellite Cells, Histology, Ultrastructure, Innervation, Contraction and Relaxation, Causes, Pathophysiology, and Treatment of Volumetric Muscle Injury. J, Biotech. and Bioprocessing 2(4); DOI: 10.31579/2766-2314/038

Copyright: ( ) 2021, Marwan T. M. Abofila, This is an open access article distributed under the Creative Commons Attribution License, which permits unrestricted use, distribution, and reproduction in any medium, provided the original work is properly cited.

\section{Abstract}

Background: Skeletal muscles are attached to bone and are responsible for the axial and appendicular movement of the skeleton and for maintenance of body position and posture.

Objectives: The present review aimed to high light on embryonic development of skeletal muscles, histological and ultrastructure, innervation, contraction and relaxation, causes, pathophysiology, and treatment of volumetric muscle injury. The heterogeneity of the muscle fibers is the base of the flexibility which allows the same muscle to be used for various tasks from continuous low-intensity activity, to repeated submaximal contractions, and to fast and strong maximal contractions. The formation of skeletal muscle begins during the fourth week of embryonic development as specialized mesodermal cells, termed myoblasts. As growth of the muscle fibers continues, aggregation into bundles occurs, and by birth, myoblast activity has ceased. Satellite cells (SCs), have single nuclei and act as regenerative cells. Satellite cells are the resident stem cells of skeletal muscle; they are considered to be self-renewing and serve to generate a population of differentiation-competent myoblasts that will participate as needed in muscle growth, repair, and regeneration. Based on various structural and functional characteristics, skeletal muscle fibres are classified into three types: Type I fibres, Type II-B fibres, and type II-A fibres. Skeletal muscle fibres vary in colour depending on their content of myoglobin. Each myofibril exhibits a repeating pattern of cross-striations which is a product of the highly ordered arrangement of the contractile proteins within it. The parallel myofibrils are arranged with their cross-striations in the register, giving rise to the regular striations seen with light microscopy in longitudinal sections of skeletal muscle. Each skeletal muscle receives at least two types of nerve fibers: motor and sensory. Striated muscles and myotendinous junctions contain sensory receptors that are encapsulated proprioceptors. The process of contraction, usually triggered by neural impulses, obeys the all-ornone law. During muscle contraction, the thin filaments slide past the thick filaments, as proposed by Huxley's sliding filament theory. In response to a muscle injury, SCs are activated and start to proliferate; at this stage, they are often referred to as either myogenic precursor cells (MPC) or myoblasts. In vitro, evidence has been presented that satellite cells can be pushed towards the adipogenic and osteogenic lineages, but contamination of such cultures from non-myogenic cells is sometimes hard to dismiss as the underlying cause of this observed multipotency. There are, however, other populations of progenitors isolated from skeletal muscle, including endothelial cells and muscle-derived stem cells (MDSCs), blood-vessel-associated mesoangioblasts, muscle side-population cells, CD133+ve cells, myoendothelial cells, and pericytes. Volumetric muscle loss (VML) is defined as the traumatic or surgical loss of skeletal muscle with resultant functional impairment. It represents a challenging clinical problem for both military and civilian medicine. VML results in severe cosmetic deformities and debilitating functional loss. In response to damage, skeletal muscle goes through a well-defined series of events including; degeneration (1 to 3days), inflammation, and regeneration (3 to 4 weeks), fibrosis, and extracellular matrix remodeling ( 3 to 6 months).. Mammalian skeletal muscle has an impressive ability to regenerate itself in response to injury. During muscle tissue repair following damage, the degree of damage and the interactions between muscle and the infiltrating inflammatory cells appear to affect the successful outcome of the muscle repair process. The transplantation of stem cells into aberrant or injured tissue has long been a central goal of regenerative medicine and tissue engineering. 
Conclusion: It can be concluded that the formation of skeletal muscle begins during the fourth week of embryonic development as specialized mesodermal cells, termed myoblasts, by birth myoblast activity has ceased. Satellite cells are considered to be selfrenewing, and serve to generate a population of differentiation-competent myoblasts. Skeletal muscle fibres are classified into three types. The process of contraction, usually triggered by neural impulses, obeys the all-or-none law. VML results in severe cosmetic deformities and debilitating functional loss. Mammalian skeletal muscle has an impressive ability to regenerate itself in response to injury. The transplantation of stem cells into aberrant or injured tissue has long been a central goal of regenerative medicine and tissue engineering.

Keywords: embryonic development of skeletal muscles, histological and ultrastructure, innervation, contraction and relaxation, volumetric muscle injury

\section{Introduction}

Skeletal muscles are attached to bone and are responsible for the axial and appendicular movement of the skeleton and maintenance of body position and posture. Also, skeletal muscles of the eye (extra-ocular muscles) provide precise eye movement [1]. Based on various structural and functional characteristics, skeletal muscle fibres are classified into three types: Type I fibres, Type II-B fibres, and type II-A fibres [2].

Mammalian skeletal muscles are heterogeneous. The functional unit of the motor system, the motor unit, is composed of a motor neuron and a bunch of muscle fibers with similar, but not identical, structural and functional properties. The heterogeneity of the muscle fibers is the base of the flexibility which allows the same muscle to be used for various tasks from continuous low-intensity activity (e.g., posture), to repeated submaximal contractions (for example, locomotion), and to fast and strong maximal contractions (jumping, kicking) [2]. Part of the myoblast population does not fuse and differentiate but remains as a group of mesenchymal cells called muscle satellite cells located on the external surface of muscle fibers inside the developing external lamina. Satellite cells proliferate and produce new muscle fibers following muscle injury [3].
Muscle contraction obeys the "all-or-none law" and is followed by muscle relaxation. Contraction effectively reduces the resting length of the muscle fiber by an amount that is equal to the sum of all shortenings that occur in all sarcomeres of that particular muscle cell [4].

\section{Objectives}

The present review aimed to high light on embryonic development of skeletal muscles, histological and ultrastructure, innervation, contraction and relaxation, causes, pathophysiology, and treatment of volumetric muscle injury.

\section{Embryonic Development of Skeletal Muscles}

The formation of skeletal muscle begins during the fourth week of embryonic development as specialized mesodermal cells, termed myoblasts, which begin rapid mitotic division. The cytoplasmic fusion of myoblasts forms what is known as myotubes. By week nine of development, these can be identified as multinucleate skeletal muscle cells, termed muscle fibers (Figure .1) [5]. By the fifth month, the muscle fibers start accumulating protein filaments important in muscle contraction. As growth of the muscle fibers continues, aggregation into bundles occurs, and by birth, myoblast activity has ceased [6].

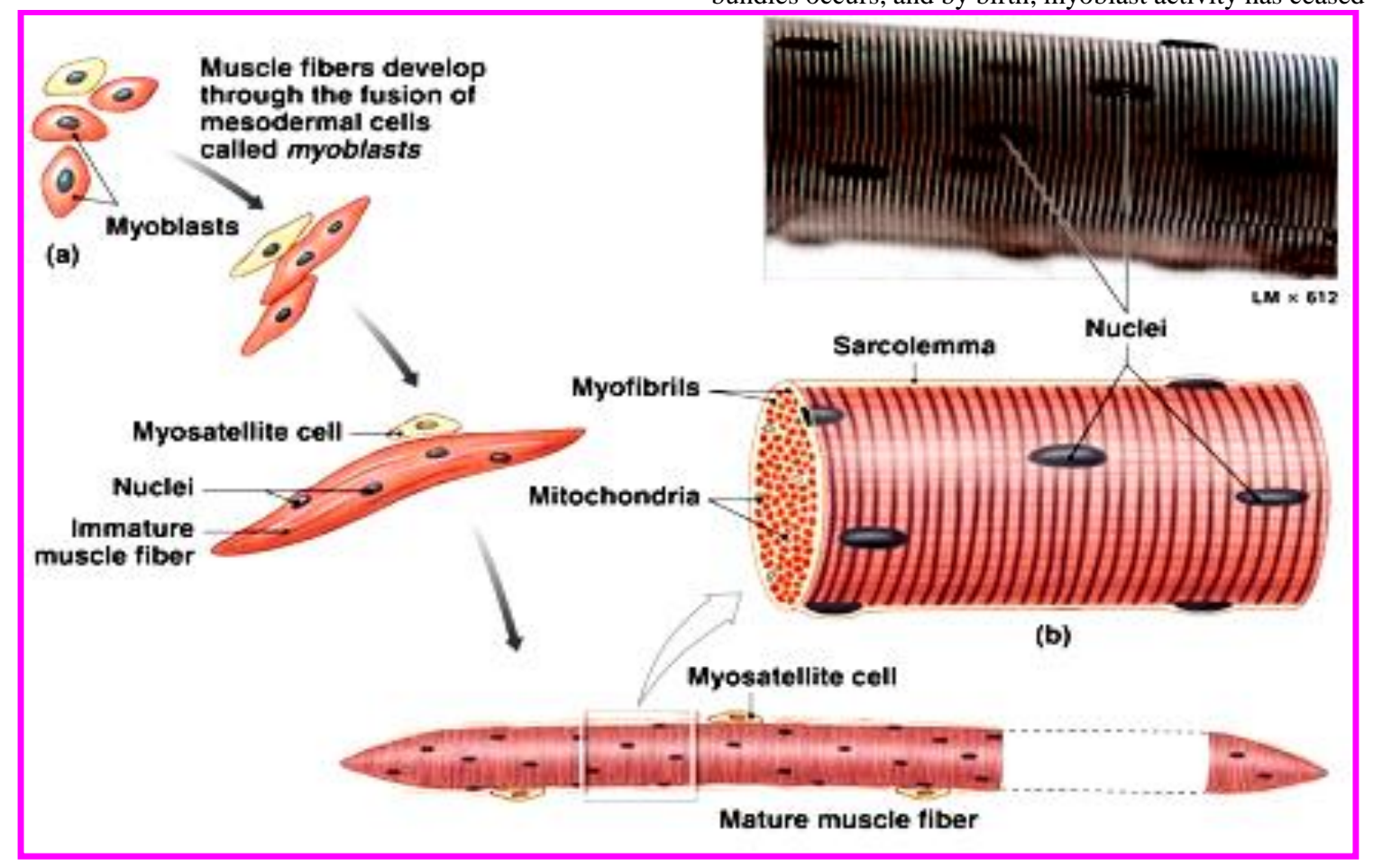

Figure 1: Embryonic development of the skeletal muscle fibers [5].

\section{Muscle Satellite Cells}


Satellite cells (SCs), have single nuclei and act as regenerative cells. They are located in shallow depressions on the muscle cell's surface, sharing the muscle fiber's external lamina. The chromatin network of the satellite cell nucleus is denser and coarser than that of the muscle fiber [4]. Satellite cells are the resident stem cells of skeletal muscle; they are considered to be self-renewing and serve to generate a population of differentiation-competent myoblasts that will participate as needed in muscle growth, repair and regeneration [7].

Satellite cells were first described by Mauro [8] and are so called due to its peripheral location on the skeletal muscle myofiber, where it lies between the sarcolemma of the myofiber cell and its surrounding basal lamina, they have unique morphological characteristics, including abundant cytoplasm, a small nucleus with increased amounts of heterochromatin and reduced organelle content. These features reflect the fact that satellite cells are mitotically quiescent and transcriptionally less active than myonuclei [9].

Satellite cells (SCs) have been shown to express different types of genetic markers, about $10 \%$ of them are (Pax $7+/$ Myf5-) stem cells, and $90 \%$ are committed myogenic progenitors (Pax7+/Myf5+) [10]. In mature muscle tissue, satellite cells occur as a small, dispersed population of mitotically and physiologically quiescent cells, marked by their expression of cellsurface markers, including syndecan-4 [11] and $\alpha 7$ integrin [12]. More recently, variation in the expression of various non-specific myogenic markers, in satellite cells, such as nestin [13], b1-integrin [14], and Syndecan-4 [15] have also been described. Despite the evident heterogeneity, the phenotypical characteristics of these subpopulations are hard to elucidate because their behavior in vitro has been difficult to investigate.

Satellite cells originate from somites [7, 16]. SCs are present in healthy adult mammalian muscle as quiescent cells and represent $2.5 \%-6 \%$ of all nuclei of a given muscle fiber. Quiescent SCs express characteristic (although not unique) markers. In the mouse, the most widely used of these markers is the transcription factor paired box 7 (Pax7) [17], which is essential for SC specification and survival [18]. In contrast, Pax3 is expressed only in quiescent SCs in a few specific muscle groups (Figure. 2) [19]. In humans, markers of both quiescent and activated SCs do not fully correspond to those in the mouse, and relatively little is known about them due to the difficulty of obtaining human tissue. For example, although CD34 is a marker of SCs in mice, it does not mark SCs in human muscle [20].

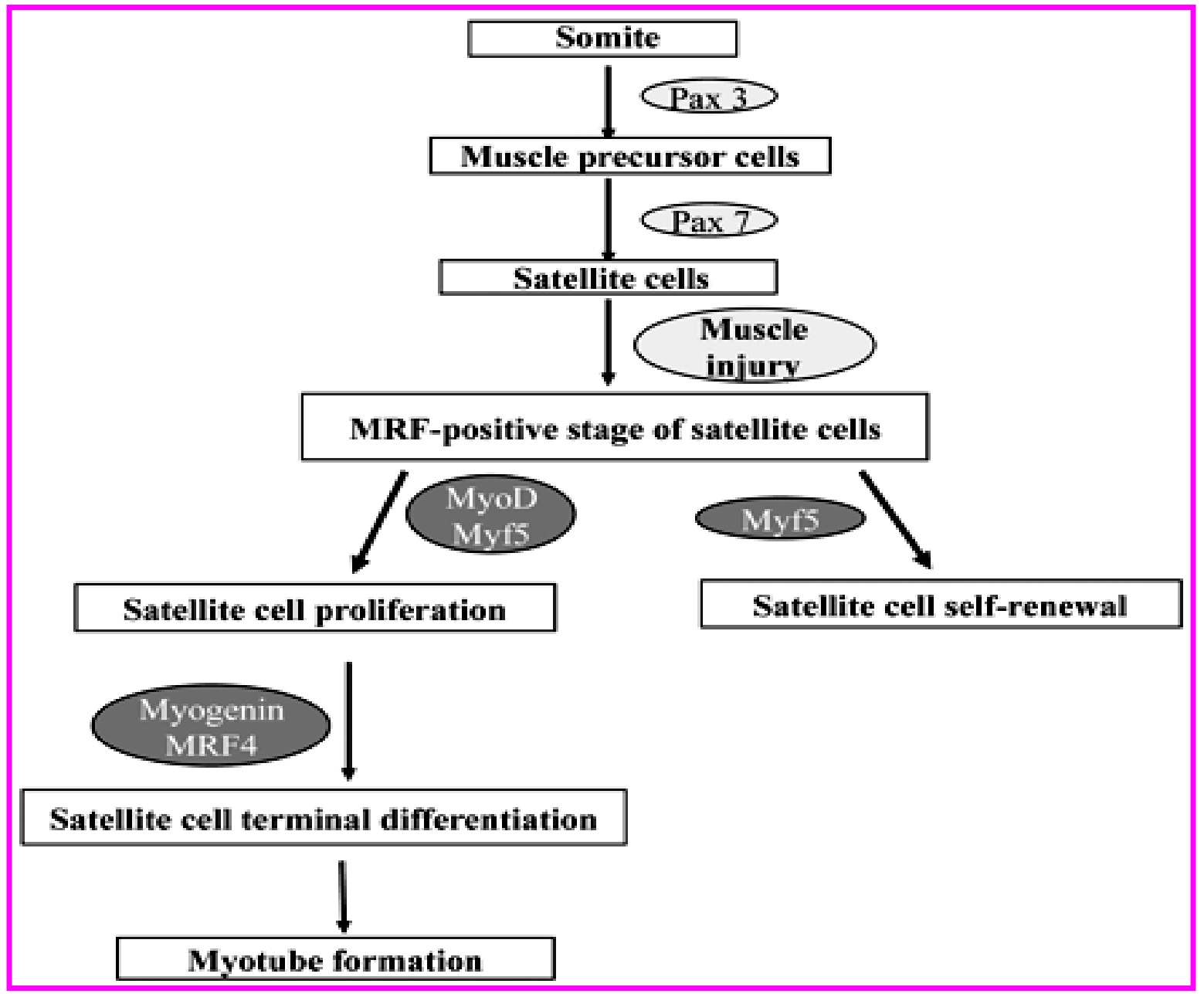

Figure 2: Satellite cell specification, activation, and differentiation during muscle development and regeneration [17].

\section{Histological organization of skeletal muscles}

Skeletal muscles are sheathed by a tough layer of connective tissue called the epimysium. The epimysium anchors muscle tissue to tendons at each end, where the epimysium becomes thicker and collagenous. It also protects muscles from friction against other muscles and bones. Within the epimysium are multiple bundles called fascicles, each of which contains 10 to 100 or more muscle fibers collectively sheathed by perimysium. Besides surrounding each fascicle, the perimysium is a 
pathway for nerves and the flow of blood within the muscle. The threadlike muscle fibers are the individual muscle cells (myofibers), and each cell is encased within its endomysium which is composed of reticular fibers and an external lamina (basal lamina) [21].

One of the most important roles of this connective tissue is to transmit the mechanical forces generated by the contracting muscle cell/fibers because individual muscle cells seldom extend from one end of a muscle to the other [3].

The muscle penetrates by blood vessels within the septa of connective tissue that made endomysium have a rich capillary network. Lymphatic vessels and larger blood vessels are found in the other connective tissue layers [3].

The cell contractile apparatus largely occupied both sarcoplasm \& the cytoplasm of each myofiber. This is made up of myofibrils arranged in sarcomeres, which are the cell contractile units. The myofibrils are longitudinally arranged cylindrical structures, each 1 to $2 \mu \mathrm{m}$ in diameter [21].

\section{Types of skeletal muscle fibers}

Skeletal muscle fibres vary in colour (red, white, and intermediate) depending on their content of myoglobin (myoglobin stores oxygen until needed by the mitochondria). Fibers of skeletal muscle contract at different rates, based on their ability to partition adenosine triphosphate (ATP). Furthermore, fibers of skeletal muscle vary regarding the processes of metabolic that they use to generate ATP. It also differs in terms of the fatigue onset. Based on various structural and functional characteristics, skeletal muscle fibres are classified into three types: Type I fibres, Type II B fibres and type II A fibres [2].

Fibers of Type I: These fibers, also known as fibers of slow-twitch or slow-oxidizing, contain myoglobin with large amounts, several mitochondria, and several blood capillaries. Fibers of type I are red, which are slow regarding the rate of split ATP, and contraction velocity, but have a high ability to generate ATP by processes of oxidative metabolic, and very resistant to fatigue. Such fibres are found in large numbers in the postural muscles of the neck [22].

Fibers of Type II-A: These fibers, also known as fibers of fast-twitch or fast-oxidizing, contain myoglobin with large amounts, several mitochondria, and several blood capillaries. Fibres of type II-A are red and resistant to fatigue which are very fast with concerning the rate of split ATP, as well as have a very high ability to generate ATP by processes of oxidative metabolic and have a rapid contraction. Such fibres are infrequently found in humans [22].

Fibers of Type II-B: These fibers, also known as fibers of fast-twitch or fast- glycolytic, contain myoglobin with low amounts but contain a large content of glycogen, and relatively few of both mitochondria and blood capillaries. Fibres of type II-B are white and easy to fatigue, geared to generate ATP by processes of anaerobic metabolic, not able to provide fibres of skeletal muscle constantly with enough ATP, split ATP at a rapid rate and have a rapid contraction rate. Such fibres are found in large numbers in the muscles of the arms [22].

In different classes of vertebrates, Fiber of muscle type diversification is observed since early stages of development. The notion of Satellite cell heterogeneity is supported by the finding that satellite cells from adult mammalian muscle tend to form fibers with a phenotype reflecting their fiber type of origin [23].
The finding that regenerating fast and slow skeletal muscle show a different myosin heavy chain (MyHC) composition when stimulated with the same impulse pattern in the absence of innervation, probably reflecting intrinsically different satellite cells [24].

\section{Ultrastructure of skeletal muscle fibers}

The very orderly arrangement of contractile proteins within each myofibril, lead to exhibits a frequent pattern of cross-striations. This can only be seen with electron microscopy. Furthermore, the parallel myofibrils are arranged with their cross-striations in the register, giving rise to the regular striations seen with light microscopy in longitudinal sections of skeletal muscle [21].

The dark bands are known as A bands ( $a$ nisotropic with polarized light) and the light bands as I bands (isotropic with polarized light). Both A and I bands are divided by narrow regions of varying intensities. A dense line, the $\mathrm{Z}$ line, also called the $\mathrm{Z}$ disc, bisects the light $\mathrm{I}$ band. Also $\mathrm{t}$ he dark band $\mathrm{A}$ is split into a less intense or light region called the $\mathrm{H}$ band. In addition, the division of the light band $\mathrm{H}$ is a narrow and dense line known as the $\mathrm{M}$ line. The $\mathrm{M}$ line is best demonstrated in electron micrographs, although in ideal H\&E preparations it can be detected in the Light microscope [1].

The pattern of A and I bands in sarcomeres is mainly due to the regular arrangement of two types of myofilaments - thin and thick - which lie parallel to the long axis of the myofibrils in a symmetrical pattern. [3].

The thick filaments occupying the A band at the center of the sarcomere are $1.6 \mu \mathrm{m}$ long and $15 \mathrm{~nm}$ wide. The thin filaments have one end attached to the $\mathrm{Z}$ line and these filaments run between and parallel to the thick filaments. Thin filaments are $8 \mathrm{~nm}$ wide and $1.0 \mathrm{~m}$ long. This arrangement makes the I band consist of part of the thin filaments that do not overlap the thick filaments, which stained lighter staining. A-bands consist mainly of thick filaments as well as interlacing portions of thin filaments. The A band shows the central light zone, the $\mathrm{H}$ zone, that corresponds to a region consisting only of the rod-like portions of the myosin molecule with no thin filaments present. Bisecting the $\mathrm{H}$ zone is the $\mathrm{M}$ line, a region where lateral connections are made between adjacent thick filaments. The main proteins present in the $\mathrm{M}$ lineage region are myomesin, a myosin-binding protein that holds thick filaments in place, and creatine kinase, which catalyzes the transfer of phosphate groups from phosphocreatine (a storage form of high-energy phosphate groups) to adenosine diphosphate (ADP), thus helping to supply adenosine triphosphate (ATP) for muscle contraction [25].

Thick and thin filaments overlap for some distance in band A. As a consequence, a cross section in the region of filament overlap shows each thick filament surrounded by six thin filaments in the form of a hexagon [3].

Thin filaments are composed of F-actin, associated with tropomyosin, which also forms a long fine polymer, and troponin, a globular complex of three subunits. Thick filaments consist primarily of myosin. Myosin and actin together represent $55 \%$ of the total protein of striated muscle.

F-actin consists of long filamentous polymers containing two strands of globular (G-actin) monomers, $5.6 \mathrm{~nm}$ in diameter, twisted around each other in a double helical formation. G-actin molecules are asymmetric and polymerize to produce a filament with polarity (Figure. 3). Each G-actin monomer contains a binding site for myosin. Actin filaments, which are anchored perpendicularly on the $\mathrm{Z}$ line by the actin-binding protein actinin, exhibit opposite polarity on each side of the line [3]. 


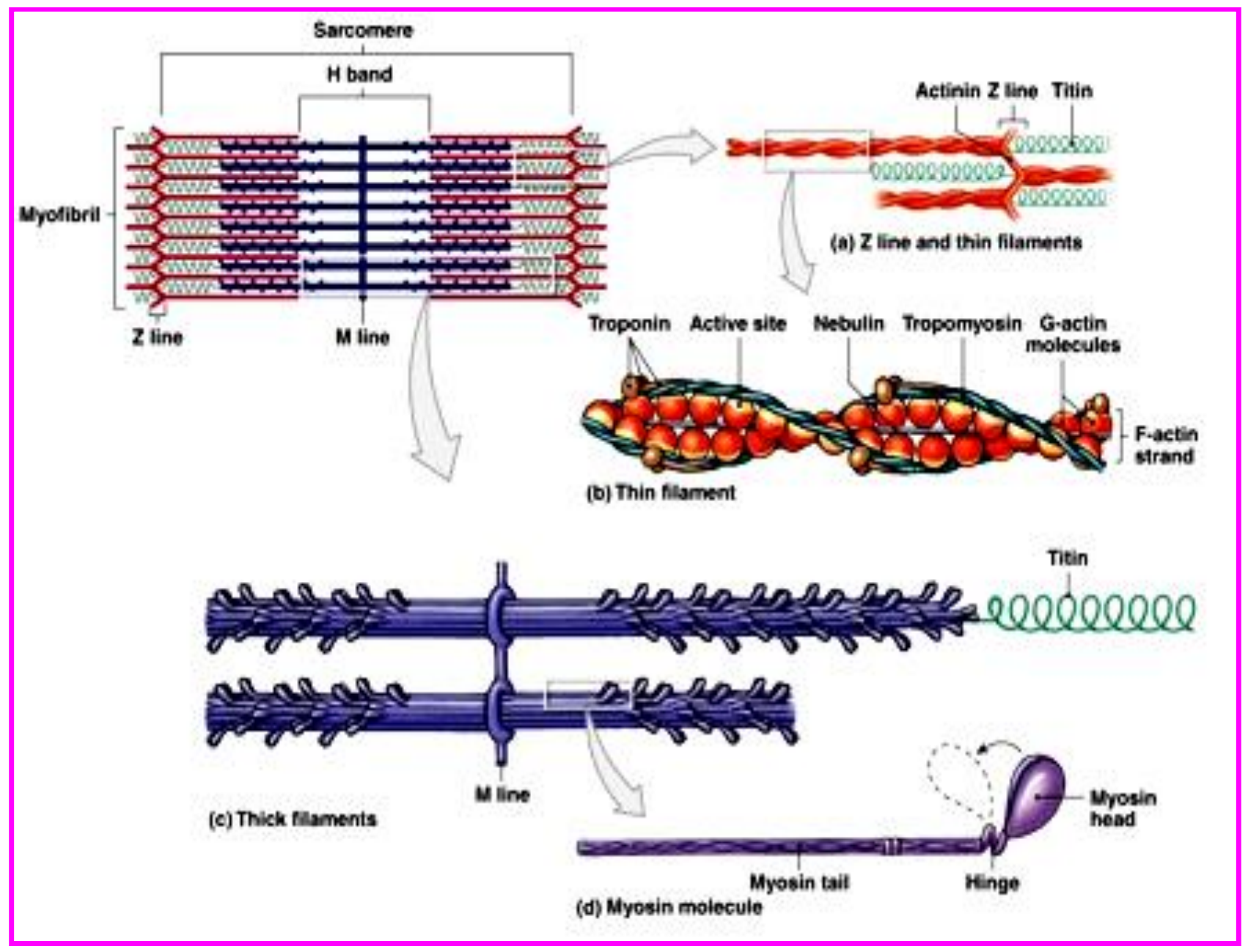

Figure 3: Ultrastructure of the sarcomere [5].

Each tropomyosin sub0unit is a long, thin molecule about $40 \mathrm{~nm}$ in length containing two polypeptide chains, which assembles to form a long polymer located in the groove between the two twisted actin strands [3].

Troponin is a complex of three subunits: TnT, which attaches to tropomyosin; TnC, which binds calcium ions; and TnI, which inhibits the actin-myosin interaction. Troponin complexes are attached at specific sites at regular intervals along each tropomyosin molecule [3].

Thick filaments are composed of myosin II molecules aligned end to end. Every thick filament consists of 200 to 300 myosin II molecules. Each myosin II molecule ( $150 \mathrm{~nm}$ in length; 2 to $3 \mathrm{~nm}$ in diameter) is composed of two identical heavy chains and two pairs of light chains. The heavy chains (two globular heads and two rod-like polypeptide chains) are wrapped around each other in an $\alpha$-helix. The heavy chains can be cleaved by trypsin into:

Light meromyosin, a rod-like tail composed of the two rod-like polypeptide chains wrapped around each other.

Heavy meromyosin, two globular heads (resembling golf clubs) with short proximal portions of the two rod-like polypeptide chains wrapped around each other [26].

Light meromyosin works in the appropriate assembly of molecules in the thick bipolar filament. Heavy meromyosin is cleaved by papain into two globular $\left(\mathrm{S}_{1}\right)$ segments; binds adenosine triphosphate (ATP) and functions in the formation of cross-bridges between the thick and thin myofilaments molecule; and a short, helical, rod-like segment $\left(\mathrm{S}_{2}\right)$. Light chains are of two types, and one of each type is associated with each $S_{1}$ subfragment of the myosin II molecule. For each heavy chain, therefore, there are two light chains. A myosin II molecule is composed of two heavy chains and four light chains [26].

Each molecule of myosin seems to contain two elastic regions, one at the junction of sub-fragments for S1 and S2 and the other at the junction of light and heavy meromyosin. The elastic region between both light and heavy meromyosins allows each molecule of myosin II to come into contact with the fine filament, forming a cross-bridge between the two types of filaments. And, the flexible region between $S_{1}$ and $S_{2}$ subfragments enables the myosin II molecule to drag the thin filament towards the middle of the sarcomere [26].

Largely five proteins maintain the structural organization of myofibrils: Titin, $\alpha$-Actinin, Cap Z, Nebulin, and Tropomodulin proteins.

Thick filaments are positioned precisely within the sarcomere with the assistance of titin, a large, linear, elastic protein. Each, a thick filament half extend two titin molecules to the adjacent $\mathrm{Z}$ disc; thus, four molecules of titin anchor a thick filament between the two $Z$ discs of each sarcomere.

Thin filaments are held in the register by the rod-shaped protein $\alpha$-actinin, a component of the $\mathrm{Z}$ disk that can bind thin filaments in parallel arrays. The excess end of the thin filament is held in place by a protein known as Cap Z, which also prevents the further, or subtraction of G-actin molecules to or from the thin filament, thus helping to maintain its 
delicate length. Furthermore, nebulin two molecules, a long inelastic protein, are coiled along the entire length of each thin filament, anchoring it further in the $\mathrm{Z}$ disk and ensuring that the specific array of thin filaments is maintained. Moreover, nebulin acts as a "ruler," ensuring the precise length of the thin filament. It is assisted in this function by the protein tropomodulin, a cap on the minus end of the thin filament that, similarly to Cap Z, prevents the addition or the deletion of G-actin molecules to or from the thin filament [4].

\section{Sarcoplasmic Reticulum and Transverse Tubule System:}

In skeletal muscle, the smooth endoplasmic reticulum (SER) is specialized for $\mathrm{Ca}^{2+}$ ion sequestration. The depolarization of this membrane of the sarcoplasmic reticulum that outcomes in the release of $\mathrm{Ca} 2+$ ions. It begins at the specialized neuromuscular junction on the muscle cell surface. Surface-initiated depolarization signals should diffuse throughout the cell to produce a release of $\mathrm{Ca} 2+$ from the internal cisterns of the sarcoplasmic reticulum. In large cells of muscle, such diffusion of the depolarization signal would lead to a contraction wave with contracting of peripheral myofibrils before those more centrally positioned. To ensure uniform contraction, fibers of skeletal muscle have a system of transverse tubules (T). These finger-like invaginations of the sarcolemma form a complex network of tubules that encircles every myofibril near the A-I band boundaries of each sarcomere [3].

\section{Innervation of skeletal muscle}

At least two types of nerve fibers receives by every skeletal muscle: sensory and motor. The motor nerve acts to stimulate contraction, while the sensory fibers are transmitted to the spindles of the muscles. Besides that, the autonomic fibers provide the vascular elements of skeletal muscle. The motor innervation specificity is the innervated muscle function. If the muscle works carefully, as some muscles in the eye do, a single motor neuron can be responsible for 5-10 fibers of skeletal muscle, while a muscle in the abdominal wall can have up to 1000 fibers under control of a single motor neuron. Each motor neuron forms muscle fibers that are controlled by a motor unit. The muscle fibers of a motor unit contract in unison and follow the all-or-none law of muscle contraction [4].

The myelinated motor nerves branch out inside the peripheral connective tissue, with each nerve producing several terminal branches. At the innervation site, the axon loses its myelin sheath and forms an expanding end located within a trough on the surface of the muscle cells. This structure is known as the myoneural junction or the motor endplate. Only the axon at this site is covered by a thin visceral extension from the cell of Schwann. Within the axon terminal, there are many synaptic vesicles and mitochondria, the previous one containing the acetylcholine of neurotransmitter. There is a space between the axon and muscle, the synaptic cleft, in which there is an amorphous basal lamina matrix from fibers of muscle. The sarcolemma at the junction is thrown into many deep junction folds, which provide a larger surface area. Below the folds of the sarcoplasm lie many nuclei and numerous mitochondria, glycogen granules, and ribosomes [3].

Myotendinous junctions and striated muscles comprise sensory receptors which are encapsulated proprioceptors (L. proprius, one's own, + capio, to take). Muscle spindles are stretch detectors that from among the muscle fascicles, which contain a capsule of connective tissue surrounding a fluid-filled space that consists of a few thin, fibers of nonstriated muscle densely filled with nuclei, and known as intrafusal fibers. Numerous axons of sensory nerves penetrate each muscle spindle and wrap around individual intrafusal fibers. Length changes in (usually stretched) of striated (extrafusal) fibers caused by body movements are detected by sensory nerves and muscle spindles transmit this information to the spinal cord. Mediate reactions of varying complexity by various types of internal and sensory fibers to maintain posture and regulate the activity of opposing muscle groups contributory in motor activities for example walking [3].

In tendons, near the insertion sites of muscle fibers, a connective tissue sheath encapsulates the large collagen bundles of the myotendinous junction. Sensory nerves penetrate this capsule and form another sensory receptor known as (Golgi) tendon organs. Tendon organs detect changes in tension within tendons produced by muscle contraction and act to inhibit motor nerve activity if tension becomes excessive. Because both of these sensory receptors detect increases in tension, they help to regulate the amount of effort required to perform movements that call for variable amounts of muscular force [3].

\section{Muscle Contraction and Relaxation}

The process of contraction, usually triggered by neural impulses, obeys the all-or-none law, in that a single muscle fiber either contracts as a result of stimulation or does not respond at all. The strength of contraction of a gross anatomical muscle, such as the biceps, is a function of the number of muscle fibers that undergo contraction. The stimulus is transferred at the neuromuscular junction. During muscle contraction, the thin filaments slide past the thick filaments, as proposed by Huxley's sliding filament theory [4].

During contraction, the I band decreases in size as thin filaments penetrate the A band. The $\mathrm{H}$ band - the part of the A band with only thick filaments - diminishes in width as the thin filaments completely overlap the thick filaments. A net result is that each sarcomere, and consequently the whole cell (fiber), is greatly shortened. The following sequence of events leads to contraction in skeletal muscle:

1. An impulse, generated along the sarcolemma, is transmitted into the interior of the fiber via the $\mathrm{T}$ tubules, where it is conveyed to the terminal cisternae of the sarcoplasmic reticulum.

2. Calcium ions leave the terminal cisternae through voltage-gated calcium release channels, enter the cytosol, and bind to the $\mathrm{TnC}$ subunit of troponin, altering its conformation.

3. Conformational change in troponin shifts the position of tropomyosin deeper into the groove, unmasking the active site (myosin-binding site) on the actin molecule.

4. ATP present on the $\mathrm{S}_{1}$ subfragment of myosin II is hydrolyzed, but both adenosine diphosphate (ADP) and inorganic phosphate $\left(\mathrm{P}_{\mathrm{i}}\right)$ remain attached to the $\mathrm{S}_{1}$ subfragment, and the complex binds to the active site on actin.

5. $\quad \mathrm{P}_{\mathrm{i}}$ is released, resulting not only in greater bond strength between the actin and myosin II but also in a conformational alteration of the $S_{1}$ subfragment.

6. ADP is also released, and the thin filament is dragged toward the center of the sarcomere ("power stroke").

7. A new ATP molecule binds to the $S_{1}$ subfragment, causing the release of the bond between actin and myosin II.

8. The attachment and release cycles must be repeated numerous times for contraction to be completed. Each attachment and release cycle requires ATP for the conversion of chemical energy into motion [4] (Figure. 4). 


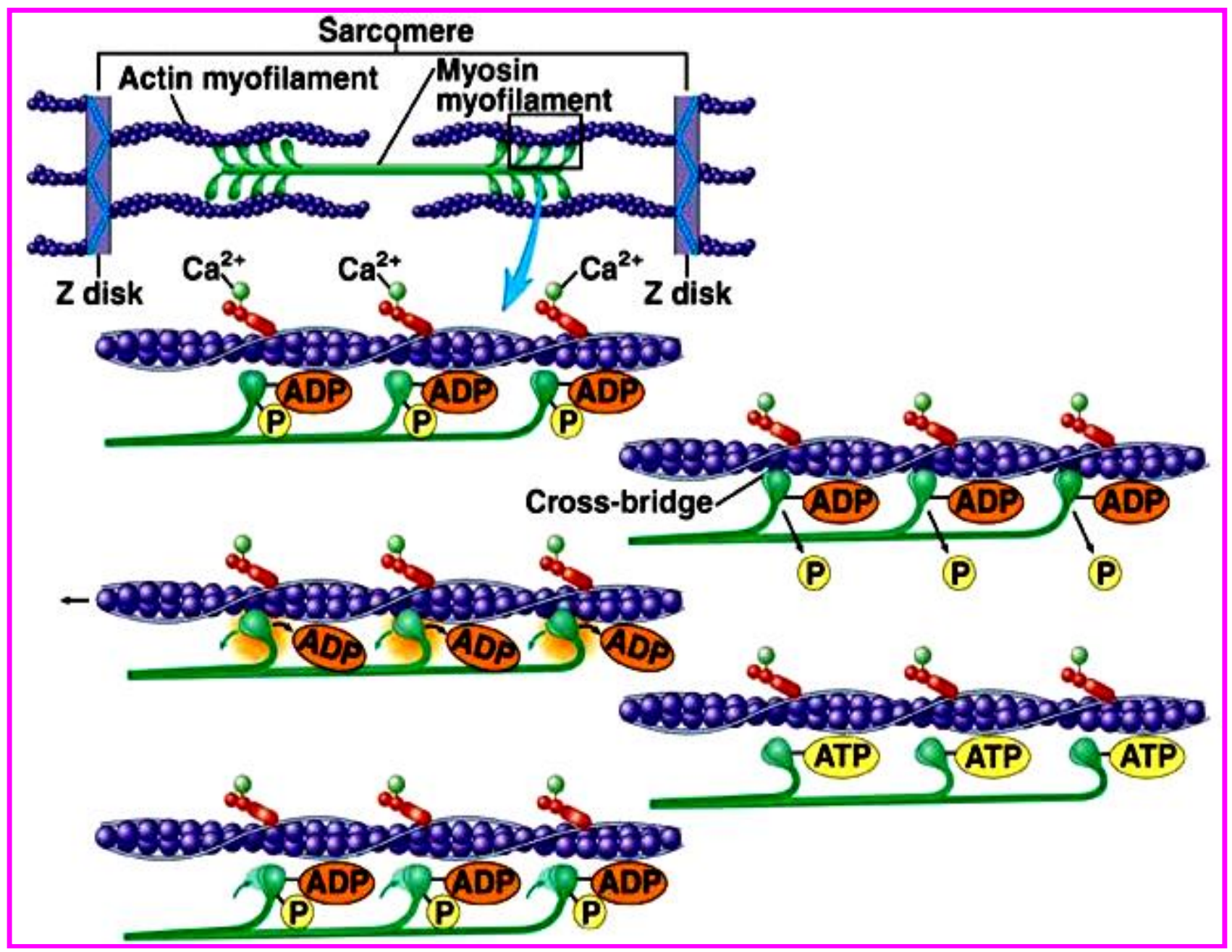

Figure 4: role of phosphate ions and ADP in muscle contraction [25].

\section{Muscle Injury}

In response to a muscle injury, Satellite cells (SCs) are activated and start to proliferate; at this stage, they are often referred to as either myogenic precursor cells (MPC) or myoblasts [27, 28]. Several signals, deriving both from damaged fibers and infiltrating cells, are involved in SC activation, including; Hepatocyte growth factor HGF [29], Fibroblast growth factor FGF [7], Insulin-like growth factor IGF [30] and Nitric oxide NO [31].

Using a new experimental maneuver that permits clear and correct isolation of SCs from the fiber of origin, it was reported for the first time, that two subpopulations of SCs coexist in fixed proportions on the single fiber: the low proliferative (LPC) and the high proliferative clones (HPC) which show alternative myogenic potential in vitro and retained also in vivo [32].

In adults, grafting an isolated myofiber with a small number of associated satellite cells [33], or even just a single fluorescence-activated cell sorting (FACS)-isolated satellite cell [34], produces many more donor-derived satellite cells in the host muscle than originally transplanted. Such amplification requires extensive proliferation from the donor satellite cells and/or their progeny, showing that self-renewal had occurred. Importantly, donor satellite cells remain viable, being able to again participate in regeneration if the muscle is damaged [33]. Donor-derived satellite cells can also be recovered from muscles after transplantation, and serially transplanted/recovered several more times, showing the extent of their potential for self-renewal [35]. Thus, as satellite cells not only generate differentiated progeny, but also maintain their own population by self-renewal, they can be classified as myogenic stem cells.

The term 'stem cell', however, also evokes thoughts of multi-potency. In vitro, evidence has been presented that satellite cells can be pushed towards the adipogenic and osteogenic lineages [36], but contamination of such cultures from non-myogenic cells is sometimes hard to dismiss as the underlying cause of this observed multipotency [37, 38]. Recent examination using recombination-based lineage tracing indicates that, although satellite cells can be stimulated to accumulate lipid, they do not undergo terminal adipogenic differentiation in vitro [38]. Furthermore, whereas exposure to bone morphogenetic proteins (BMPs) inhibits myogenic differentiation in satellite cells in vitro, it does not result in any overt change to the osteogenic lineage [39]. In vivo, there is also a negligible $(<5 \%)$ contribution of satellite cells to BMP-mediated ectopic osteogenesis [40]. Therefore, satellite cells can be considered monopotent muscle-resident myogenic stem cells.

Multiple lines of evidence point to functional heterogeneity of satellite cells, which indicates that they do not all have stem cell characteristics. Not only do satellite cell populations from different muscles exhibit heterogeneity in their proliferation rate, clonogenic capacity, extent and rate of differentiation, and ability to self-renew, these variations also exist between satellite cells of the same muscle $[37,41]$. Heterogeneity is also 
revealed by transplantation studies, as only a limited number of grafts result in large numbers of new satellite cells being produced, so extensive self-renewal does not appear to be a universal feature of satellite cells [33, 34].
There are, however, other populations of progenitors isolated from skeletal muscle, including endothelial cells and muscle derived stem cells (MDSCs) [42], blood-vessel associated mesoangioblasts [43], muscle side-population cells [44], CD133+ve cells [45], myoendothelial cells [46] and pericytes [47] (Figure. 5) .

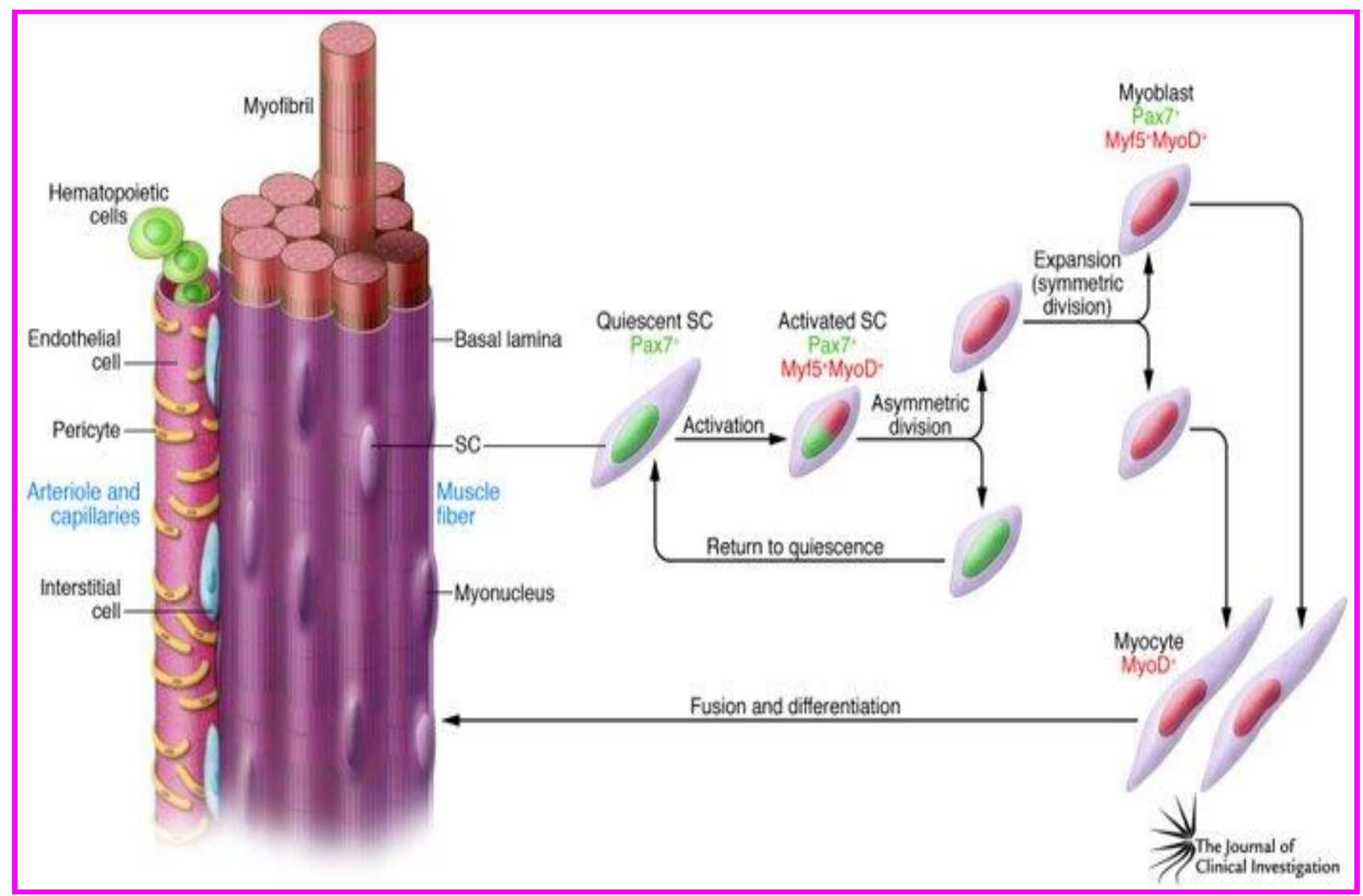

Figure 5: Asymmetric cell division during activation of SCs. SC activation in vivo is followed by an asymmetric division [48].

Endothelial cells and muscle derived stem cells MDSCs are multipotent cells, and may involve in skeletal muscle regeneration [20].

Pericytes and mesoangioblasts cells contribute to muscle regeneration after intra-arterial delivery [45].

Since the discovery of (MDSCs), there is convincing evidence that these cells are likely derived from the vascular endothelium and could shares along with satellite cells in regeneration of injuried skeletal muscle [46] (Figure. 6).

MDSCs can be efficiently transduced with antifibrotic and regenerative factors that may enhance skeletal muscle healing [49].
Human (MDSCs) are Characterized by expression of CD13 and to a lesser extent CD10 and CD56, on these cells [50], as well as the lack of hematopoietic marker expression, including CD45. These cells were named mesenchymal stem cells for their ability to differentiate into the mesodermal phenotypes (Figure. 4). For clarity, it should be noted that a population of bone marrow stromal cells has also been termed mesenchymal stem cells, referring to their differentiation potential. Marrow-derived mesenchymal stem cells have been described as expressing the proteins CD29 CD44, CD71, CD90, CD106, CD120a and CD124. It is not clear at this point if these two populations are the same, are distinct, or represent different stages of maturation of the same lineage [51]. 


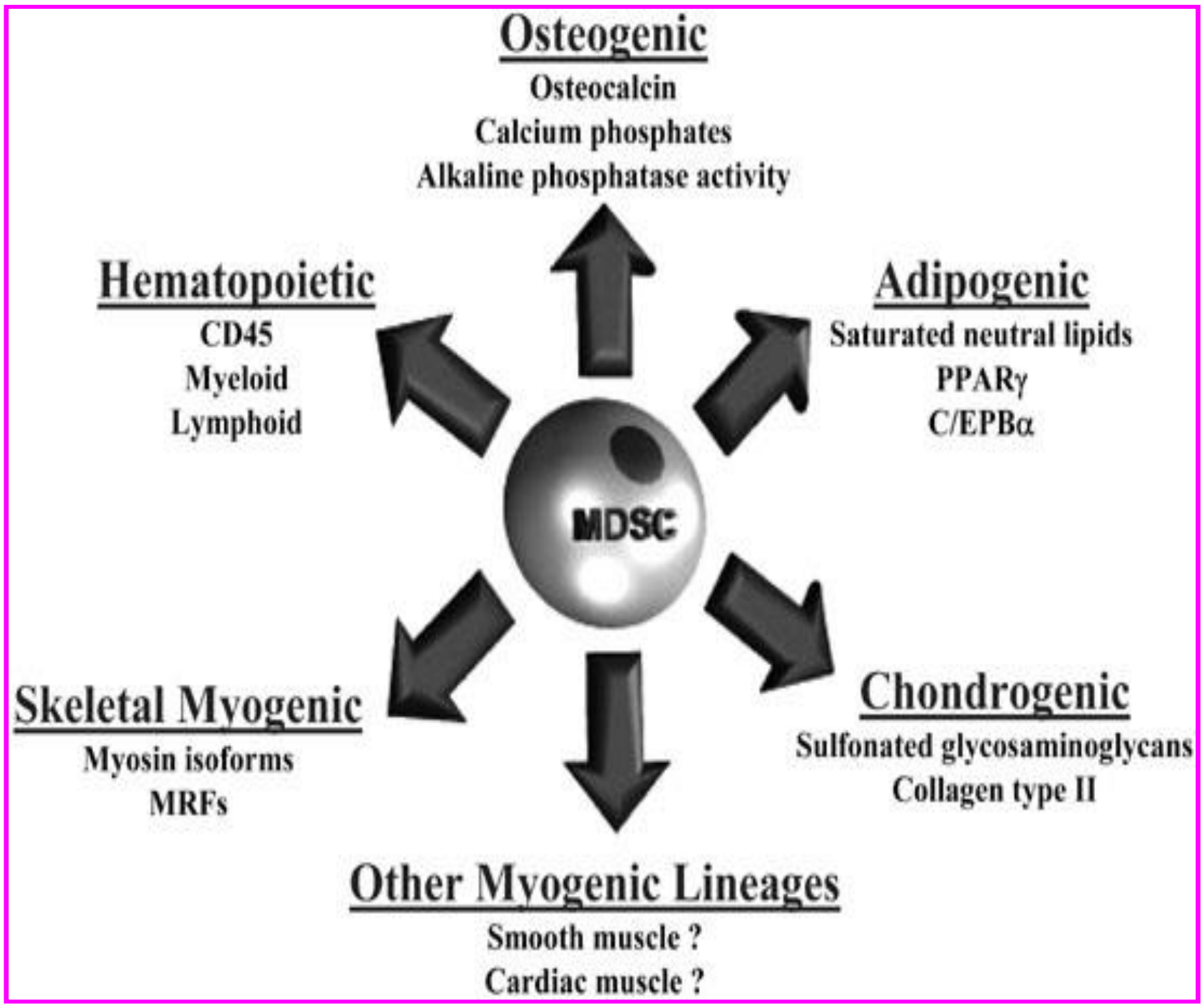

Figure 6: Multilineage differentiation of muscle-derived stem cells [52].

\subsection{Volumetric Skeletal Muscle Injury}

Volumetric muscle loss (VML) is defined as the traumatic or surgical loss of skeletal muscle with resultant functional impairment [26].

\subsection{Causes of volumetric muscle loss}

Volumetric muscle loss represents a challenging clinical problem for both military and civilian medicine. In military medicine, it occurs primarily from penetrating soft tissue injuries as a result of explosions, and as a consequence of excision and debridement of devitalized muscle tissue following extremity compartment syndrome [53].

In civilian medicine, VML is often associated with penetrating trauma from motor vehicle accidents and sport activities and the implications for the athlete, his/her coach and team may be catastrophic if the injury occurs at a critical time in the athlete's diary. Cranio-maxillo-facial trauma is common on the battlefield [54]. In all cases, VML results in severe cosmetic deformities and debilitating functional loss [26].

\subsection{Basic Pathophysiology of Skeletal Muscle Injury}

In response to damage, skeletal muscle goes through a well-defined series of events including; degeneration (1to3days), inflammation and regeneration ( 3 to 4 weeks), fibrosis and extracellular matrix remodeling (3 to 6 months) [9]. The last two phases tend to overlap, (Figure. 7). Ultimately, repair is the result of resident muscle stem cells, known as satellite cells, which proliferate, differentiate, and fuse with existing myofibers or form new myofibers [55]. The normal repair mechanisms, however, are not sufficient for the repair of VML (Kin, 2007). 


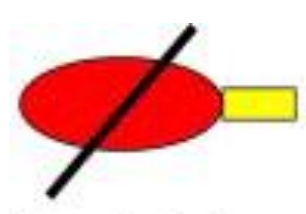

Muscle Injury

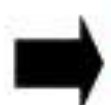

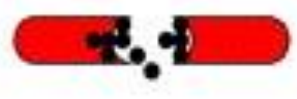

Degeneration

-Sarcolemma destruction

-Influx of Calcium

-Hematoma formation

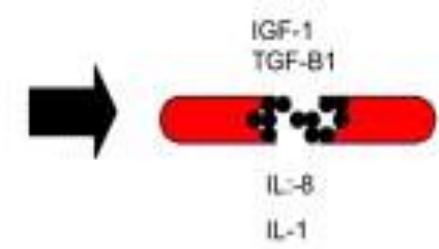

Inflammation

-Infiltration by neutrophils, macro-

phages, and $\mathrm{T}$ lymphocytes

-Release of cytokines

-Neovascularization of hematoma

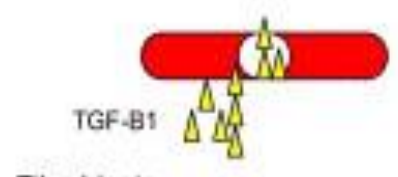

Fibroblasts

Fibrosis

-Myofibroblast proliferation

-Proliferation of ECM

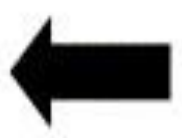

Proliferating myoblasts

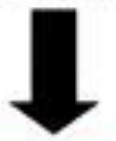

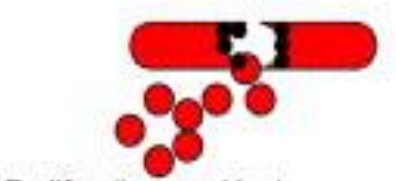

Regeneration

-Activation of satellite cells

-Myoblast proliferation

\section{Fibrosis}

\section{Regeneration}

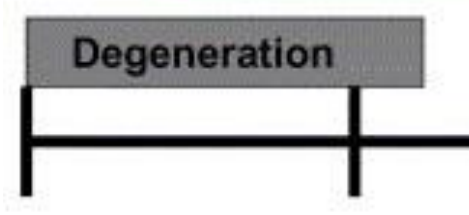

Zero
One
Two

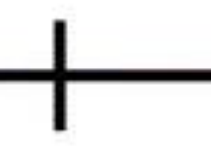

Weeks

Figure 7: Phases and timeline of phases of healing after injury [57].

Mammalian skeletal muscle has an impressive ability to regenerate itself in response to injury [58]. Skeletal muscle repair is a highly synchronized process involving the activation of various cellular and molecular responses, where the coordination between inflammation and regeneration is crucial for the beneficial outcome of the repair process following muscle damage [59].

During muscle tissue repair following damage, the degree of damage and the interactions between muscle and the infiltrating inflammatory cells appear to affect the successful outcome of the muscle repair process. Muscle regeneration depends on a balance between pro-inflammatory and anti-inflammatory factors that determine whether the damage will be resolved with muscle fiber replacement and reconstitution of a functional contractile apparatus, or with scar formation [60]. Although the phases of the repair process are similar after different causes of damage, the kinetics and amplitude of each phase may depend on the particular muscle damaged, the extent of damage, or the damage model used [9].

Immediately following injury, there is a phase of degeneration, which is initiated by the release of proteases into the tissue stroma; these proteases auto digest myofibers and thereby, release tissue debris along the zone of injury [9]. It has been proposed that Tumor necrosis factor- $\alpha$ (TNF $\alpha)$ seems to participate in the muscle protein loss during the degenerative phase of muscle regeneration, and promotes the activation of nuclear

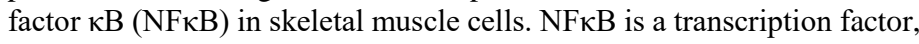
which activation alters gene expression and causes proteolysis. In vitro and in vivo data indicate that $\mathrm{TNF} \alpha$ promotes the expression of atrogin- 
1, leading to the catabolism of muscle proteins. This is a result of the activation of the ubiquitin/proteasome pathway in muscle fibers [61, 62].

A rapid necrosis of myofibers is observed. This event is characterized by disruption of the myofiber sarcolemma and results in increased myofiber permeability. As a consequence of the disruption of the myofiber's integrity, the serum levels of muscle proteins, such as creatine kinase, are increased since these proteins are normally restricted to the myofiber cytosol [63]. Within the time frame that this occurs, there is a chemotaxis of neutrophils; the first inflammatory cells to invade the injured muscle. Recent reports suggest that an important increase in their number is observed 1-6 $\mathrm{h}$ after muscle damage [64].

About 48 hours after the injury, the primary cells which predominate at the site of injured muscle are macrophages. These cells migrate to the damaged area through the blood stream. Thus, in the case of significant damage of the blood supply to the injured area, regeneration cannot take place until new blood vessels penetrate the area. After the infiltration, macrophages phagocytose cellular debris and remove the disrupted myofilaments, other cytosolic structures and the damaged sarcolemma. Apart from that, macrophages also activate myogenic cells. It appears that the main histopathological characteristics of the early phase of muscle injury are muscle fiber necrosis and an increased number of non-muscles mononucleated cells within the injured area [65].

Although it appears that macrophages may in part be a culprit by initiating inflammatory response, some studies indicate that these cells also secrete various growth factors that directly contribute to tissue regeneration and activation of repair processes necessary for successful recovery from the damage. Additionally, macrophages stimulate the paracrine release of cytokines together with chemotactic factors by $\mathrm{T}$ cells, which may locally recruit progenitor and satellite cells towards muscle regeneration [66].

Some of the critical cytokines that orchestrate this local response include, interleukins [IL]-1, -6 , and -8 as well as hepatocyte growth factor (HGF), Fibroblast growth factor (FGF) and insulin growth factor [IGF]-1. It is clear from this initial sequence of events that the inflammatory response may be conducive to the repair of skeletal muscle after injury [67].

Interleukin-6 (IL-6) is a cytokine with a major role in the regulation of the inflammation process after muscle injury [68]. IL-6 can be both a factor that induces proteolysis of damaged myofibers and a proliferation signal for satellite cells to replace the destroyed muscle tissue. Some studies suggest that skeletal muscle can produce IL-6 in response to exercise as well as inflammation and injury $[69,70]$.

Hepatocyte growth factor (HGF) and insulin-like growth factor-1 (IGF1) are mainly expressed during the regeneration process. Furthermore, histochemical analysis showed that HGF is a protein which is bound to the extracellular matrix in muscle tissue and is released in response to injury. HGF is believed to play a fundamental role during muscle regeneration, especially during the initial phase of muscle repair, and is considered to be essential for effective muscle regeneration [9]. HGF is believed to promote the quiescent satellite cells to enter the cell cycle [29], and expressed mainly during early stages of regeneration, and may, therefore, be available to bind to specific receptors on satellite cells, leading to their activation. It has also been proposed that HGF inhibits the differentiation of myogenic precursor cells [71]. Finally it should be mentioned that HGF could stimulate satellite cells and myogenic precursor cells migration to the site of injury [9].

Fibroblast growth factor (FGF); belongs to a family of cytokines that control cell proliferation, cell differentiation. Several members of the FGF family are expressed in developing skeletal muscle, but FGF-6 is the only one that seems to participate in muscle repair. The high amounts of FGFs, which are released within the short period of inflammation after tissue disruption, may induce satellite cells to proliferate and partly cause the chemotaxis of further muscle precursor cells. Today, it is known that the expression of FGF-6 is stimulated after skeletal muscle injury. FGF-6 induces satellite cell adhesion and compromises their ability to differentiate into myotubes. FGF-6 stimulates the proliferation of satellite cells and induces the expression of genes required for their terminal differentiation [7, 72, and 73].

Insulin growth factor (IGF-1) is important as a survival signal for satellite cells during regeneration and strongly expressed by macrophages and myoblasts during myotube formation and the differentiation process [30, 74]. Moreover, IGF-I promotes muscle cell survival during the initial phase of their differentiation [75].

Equally important is the role of Tumor necrosis factor- $\alpha$ TNF $\alpha$ during the regeneration phase. After skeletal muscle injury TNF $\alpha$ is released not only by infiltrating macrophages, but also by injured muscle fibers [76]. Its expression remains at high levels during the repair process and returns to normal levels several days post-injury [77]. This expression profile, along with in vitro studies, suggests that TNF $\alpha$ has a double role during muscle regeneration: it is both a competence factor (activating satellite cells to enter the cell cycle) and a progression factor (enhancing satellite cell proliferation), once it has been initiated, perhaps via activating the expression of c-fos gene, well known as an important cell growth regulator) [62].

The subsequent phase of myofiber regeneration may begin as early as 24 hours following injury, as evidenced by the cytokine-mediated induction of local satellite cells which previously lie dormant between the basal lamina and sarcolemma. It is not until at least 3 to 5 days after injury, however, that the complete formation of new, centronucleated myofibers can be detected histologically [78].

The characteristics of muscle regeneration are: (a) newly formed fibers are basophilic and this reflects a high protein synthesis. (b) during regeneration, cell fusion is focal to the injured site rather than diffused within the muscle tissue, and (c) the fibers are split, which is probably due to the incomplete fusion of fibers regenerating within the same basal lamina. When fusion of myogenic cells is completed, the size of the newly formed myofibers increases and myonuclei move to the periphery of the fiber. Finally, the new muscle tissue is the same as uninjured muscle, not only morphologically but also functionally [79].

It is likely that a crucial event in the regeneration phase is the differentiation of satellite cells into large numbers of myotubes and myofibers of within just a few days. To date, these progenitor cells are perhaps the best characterized and are often referred to as "muscle stem cells" given their predilection to the myogenic lineage [16].

The progression of activated SCs toward myogenic differentiation followed by fusion into regenerating fibers. The whole process takes approximately 7 days in the mouse while the complete process of regeneration to reform normal tissue architecture typically requires 3 to 4 weeks [80], during which time SCs undergo different fates, giving rise to a few Pax7+ve cells return to quiescence (to maintain the progenitor pool), and many Pax7+ve cells, which are committed to differentiation (Figure. 8) [81]. 

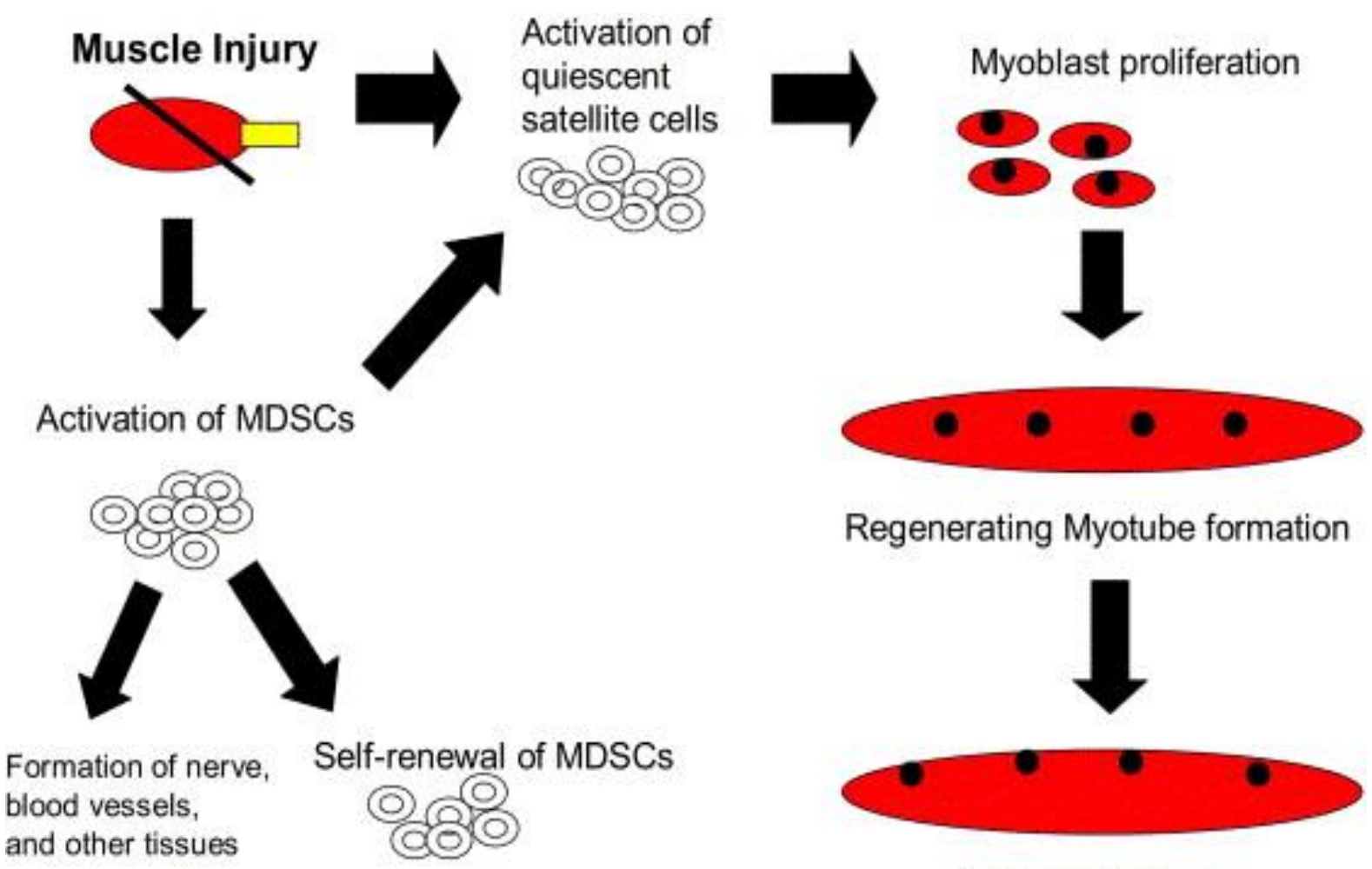

Mature Myofiber

Figure 8: Muscle regeneration after injury [57].

Perhaps the greatest limitation for patients that results from the pathophysiology of skeletal muscle injury is the formation of dense fibrotic scar tissue. It is clear that fibrosis is induced by a deleterious rise in the cytokine transforming growth factor (TGF)-B1 after injury [82]. The TGF-b1 is a small family of multifunctional growth factor proteins. It has the ability to bind to extracellular proteins and to be stored in the ECM until activation by a physiological process, such as wound healing. After injury, TGF-b1 is released by degranulating platelets at the site of injury and autoinduces its own production by resident cells, such as smooth myogenic cells. Following the denervation and the ischemia of skeletal muscles, TGF-b1 is expressed by regenerating muscles within the first days after a trauma [83].

In the presence of this cytokine, myogenic cells differentiate into myofibroblasts that produce collagen type I, the major component of fibrotic tissue [84]. Ultimately, fibrosis can prevent patients from returning to their baseline function, in part by preventing the formation of new axons toward myofibers and contributes to a decline in muscle contractility and range of motion. The pain that results from fibrosis is also a limiting factor in the recovery of patients during rehabilitation [85].

Although not currently used clinically in this capacity, several agents that block $\mathrm{TGFb} 1$ have proven to be remarkably antifibrotic, including gamma-interferon, suramin, and decorin [86, 87]. When suramin was injected immediately or 7 days after the injury, it had only a minor effect on muscle fibrosis. However, when a high dose of suramin was injected 14 days after injury, it prevented fibrosis more effectively than did a lower concentration or no suramin. There were more regenerating myofibers in all the suramin-treated groups than in the control groups. Just as the prevention of fibrosis, the number of regenerating myofibers was dose dependent. Side effects of suramin are adrenocortical insufficiency, malaise, neuropathy, and corneal deposits. Occasionally, neutropenia, thrombocytopenia, and renal failure may occur [88].
Fukushima et al., [89] found that the injection of decorin at 10 and 15 days after injury significantly decreased the amount of fibrosis. Decorin had the additional advantage of enhancing the regeneration of the injured muscle. There seemed to be a dose-response effect.

Therapeutic interventions to improve outcomes following muscle injuries revolve around 3 concepts: enhancing regeneration, blocking fibrosis, and regulating inflammation [57].

Traditional therapies, usually conservative such as non-steroidal antiinflammatory administration, rest, antioxidant therapy and physical therapy have generally not been helpful in preventing fibrosis and permanent muscle contracture, which leads to functional impairment. Generally, they are not sufficient to enhance muscle regeneration and prevent fibrosis [90].

Extracellular matrix remodeling (ECM); For many years, the ECM was believed to play a passive role during muscle development and regeneration, acting simply as a scaffold for the arrangement of the cells within tissues. Today, it is believed that proteoglycans, collagen, metalloproteinases and other elements of the ECM might play an energetic key role during muscle development [91, 92]. Although the exact function of these other elements in muscle regeneration is not well understood, the similarities between skeletal muscle embryogenesis and regeneration might indicate a similar role of the ECM during these two processes. Satellite cells are surrounded by ECM components and remodeling of these ECM molecules has been seen in many myoblast and muscle cell responses such as migration, fusion and myotube maturation [93].

Moreover, the ECM acts as a reservoir of growth factors. For instance, TGF $\beta$ binds to decorin, a heparan sulfate proteoglycan, and is stored in the ECM. Matrix degeneration after injury can release these growth factors, which can then transduce their signals to the cells and regulate the 
regeneration process [94]. The ECM may also participate in the regulation of the activity of various growth factors. Molecular studies have proven that FGF and TGF $\beta$ can bind to extracellular proteoglycans [83]. FGFbinding to syndecan-1 and glypican seems to be essential for the function of FGF during muscle development and repair, while the binding of TGF to decorin inactivates TGF $[83,92]$. Therefore, the ECM may be involved in the precise regulation of the activity of growth factors during muscle regeneration

Moreover, it is notable that the ECM possibly participates in satellite cell migration to the site of injury $[92,95]$. Cell migration involves a series of complex cell ECM interactions, including adhesion to ECM through integrins, contraction of the cytoskeleton, translocation and release of cell-ECM contact [92]. The right function of integrins is essential for the migration process and may also have a critical role during muscle repair. Furthermore, various studies suggest that interactions between neuron axon and Schwann cells as well as between Schwann cells and the ECM are essential for nerve growth during peripheral nerve regeneration. This suggests a possible pole for ECM in the reinnervation of injured skeletal muscle [96]. Besides, ECM may also participate in signaling pathways essential for muscle differentiation, as myogenin alone cannot stimulate cell terminal differentiation [91].

Another important element of the ECM is the family of matrix metalloproteinases (MMPs) which are a family of $\mathrm{Ca}$ - dependent endopeptidases able to cleave most of the ECM components [96]. Their expression is highly regulated during both muscle development and repair [83, 92], and it appears that, in such conditions, MMPs and plasminogen activators act in concert. Thus, plasmin activity together with MMPs is needed to complete a wound healing process; urokinase-type plasminogen activator (UPA) complex participates in fibrinolysis while MMPs have the capacity to split fibrin by acting as pericellular fibrinolysins [92, 97].

To date, data indicate that MMPs are involved in myoblast migration to the site of injury [96]. Urokinase-type plasminogen activator (uPA) and plasmin are implicated in several non-fibrinolytic processes, which lead to ECM degradation, either directly by proteolytic cleavage of ECM components, or indirectly through the activation of latent MMPs [98, 99]. Indeed, a proteolytic activation cascade initiated by uPA/plasmin is involved in MMP activation during muscle regeneration. Plasmin can directly activate several MMPs in vivo through proteolysis and it appears that the activation of MMP-2 and MMP-9 during skeletal muscle regeneration could be mediated by plasmin [99].

Moreover, activated satellite cells can synthesize and secrete MMP-2 and 9 and may be involved in the ECM remodeling after injury, Other MMPs, such as MMP-7, are thought to take part in the fusion of myoblasts [96]. Furthermore, MMPs are possibly involved in the transmission of growth factor signals during muscle repair $[83,92,96]$.

\subsection{Treatment of volumetric muscle injury}

In the 21 st century, stem cell therapy has generated a lot of interest in its potential for clinical use in various incurable \& chronic diseases [100, 101]. The current standard of care for volumetric muscle injury is to transfer autologous tissue (muscle flaps) using donor tissue from other areas of the victim's body. Recent reports describe functional free muscle transplantation in the elbow [102], but these procedures were associated with significant donor-site morbidity and are not yet applicable to large defects of load-bearing muscles [103]. The transplantation of stem cells into aberrant or injured tissue has long been a central goal of regenerative medicine and tissue engineering [91].

In addition, nutritional and environmental epigenetics are involved with the repression of anti-aging genes (Sirt 1) that alter gene expression at the cellular level. as a result of changes in cellular chromatin structure, DNA methylation, and histone modifications with relevance to multiple organ dysfunction syndrome [104]. Future research involved with nutritional researches and the maintenance of Sirt 1 transcriptional control is critical to the prevention medicine and correction in epigenetic modifications induced by unhealthy diets or environmental xenobiotics [105] involved in nuclear receptor dysfunction such as the nuclear receptor of anti-aging genes Sirt 1 [106], that determines the survival of man and various species with relevance to toxicity to mitochondria in neurons $[107,108]$ and cells in peripheral tissues [109-119]. which lead to mitophagy in various tissues [104].

In the developed and developing world nutritional interventions have become essential to prevent Diseases and to maintain the metabolism of glucose, fatty acids, cholesterol, amyloid beta, bile acids and xenobiotics. The World Health Organization has reported that cardiovascular disease is the most prevalent global chronic disease that may be connected to the alarming death rate in various communities. Unhealthy western diets and lifestyles lead to circadian rhythm disorders with defective nutrient and caffeine metabolism associated with cardiovascular disease in the developed world. Caffeine doses in various global populations should be reassessed with relevance to defective anti-aging genes and accelerated mitochondrial apoptosis. Delayed caffeine and xenobiotic metabolism with zinc/magnesium deficiency may be associated to other organ diseases such as gall bladder disease, cardiovascular disease and pancreatic disease in the developing world [120].

Interests in anti-aging therapy with appetite regulation improve an individual's survival to various chronic diseases [105]. Despite the many studies examining the expression of the anti-aging gene Sirtuin 1 (Sirt 1) with the role of its in the maintenance of other cellular anti-aging genes involved in cell circadian rhythm, senescence, and apoptosis in various models of aging [121], but few studies have focused on the translational effects of SIRT1 expression in muscle to functional relevance [122].

Nowadays, regenerative medicine and tissue engineering for VML therapy is an important treatment for self-renewal and regeneration . while the advancements in skeletal muscle tissue engineering have been remarkable, there are stills several aspects which can be implemented. For example, gene editing with CRISPR/Cas9 can be very beneficial in correcting genetic defects in patient cells thus using the resulting combinations in transplantation procedures. There is no doubt that, once these aspects are improved, the engineering of skeletal muscle tissue using stem cells based therapies will lead to considerable advances in the field of regenerative and personalized medicine [123].

Other researchers have suggested that a biofabrication approach to quickly restore mass of skeletal muscle, functionality and $3 \mathrm{D}$ histoarchitecture. By recapitulating muscle anisotropic organization on a microscopic scale, they have been shown to effectively guide cell differentiation and myobundl formation both in vitro and in vivo. Note, during implantation, the biofabricated myosubstitutes favored the formation of new blood vessels and neuromuscular junctions - essential aspects for cell survival and muscle contractile functions - as well as advanced muscle mass and recovery of muscle mass strength. Overall, these strategies represent a solid foundation with further testing and improvements for large animal myosubstitutes, which can be successfully translated into a promising platform in clinical scenarios for reconstructive therapy for patients with VML [124].

\section{Conclusion}

It can be concluded that the formation of skeletal muscle begins during the fourth week of embryonic development as specialized mesodermal cells, termed myoblasts, by birth myoblast activity has ceased. Satellite cells are considered to be self-renewing, and serve to generate a population of differentiation-competent myoblasts. Skeletal muscle fibres 
are classified into three types. The process of contraction, usually triggered by neural impulses, obeys the all-or-none law. VML results in severe cosmetic deformities and debilitating functional loss. Mammalian skeletal muscle has an impressive ability to regenerate itself in response to injury. The transplantation of stem cells into aberrant or injured tissue has long been a central goal of regenerative medicine and tissue engineering.

\section{References}

1. Ross MH, and powlina W (2011) A histology text and atlas with cell and molecular biology. 6th ed. Lippincott, williams and wilkins, USA. P: 311-326.

2. Schiaffino $S$ (2010) Fibre types in skeletal muscle: a personal account. Physiol; 199: 451-463.

3. Junqueira LC and Carneiro J (2010) Basic Histology Text and Atlas, 12th ed, Mc Graw-Hill, New York, london, Toronto. P: 167-178.

4. Gartner PL and Hiatt LJ (2007) Color text book of Histology, 3rd ed, Elsevier Health Science Churchill living stone, Philadelphia, PA, USA, China. P: 157-183.

5. Frederic H and Martini M (2006) Anatomy \& Physiology, 7th Edition. New York, New Delhi. P; 283-325.

6. Maclean S, Khan WS, Malik AA, Arnold and Snow M. (2011) The potential of stem cells in the treatment of skeletal muscle injury and disease. Stem cells international; (10):1155-1165.

7. Shi X and Garry DJ (2006) Muscle stem cells in development, regeneration, and disease. Genes Dev; 20: 1692-1708.

8. Mauro A (1961) Satellite cell of skeletal muscle fibers. J Biophys Biochem Cytol; 9:493-495.

9. Charge SB and Rudnicki MA (2004) Cellular and molecular regulation of muscle regeneration. $J$ Cell Sci; 12: 84-92.

10. Kuang S, Kuroda K, Le Grand F and Rudnicki MA (2007) Asymmetric self-renewal and commitment of satellite stem cells in muscle. J Cell Biol; 129: 999-1010.

11. Cornelison DDW, Filla MS, Stanley HM, Rapraeger AC and Olwin BB (2001) Syndecan-3 and syndecan-4 specifically mark skeletal muscle satellite cells and are implicated in satellite cell maintenance and muscle regeneration. Dev Biol; 239:79-94.

12. Blanco-Bose WE, Yao CC, Kramer RH and Blau HM (2001) Purification of mouse primary myoblasts based on alpha 7 integrin expression. Exp Cell Res; 265:212-220.

13. Day K, Shefer G, Richardson JB, Enikolopov G and YablonkaReuveni Z (2007) Nestin-GFP reporter expression defines the quiescent state of skeletal muscle satellite cells. Dev Biol; 304: 246-259.

14. Cerletti M, Jurga S, Witczak CA, Hirshman MF and Shadrach JL (2008) Highly efficient, functional engraftment of skeletal muscle stem cells in dystrophic muscle. J Cell Sci; 134: 37-47.

15. Tanaka KK, Hall JK, Troy AA, Cornelison DD and Majka SM (2009) Syndecan-4-expressing muscle progenitor cells in the SP engraft as satellite cells during muscle regeneration. Cell Stem Cell; 4: 217-225.

16. Sambasivan R and Tajbakhsh S (2007) Skeletal muscle stem cell birth and properties. Semin Cell Dev Biol; 18(6): 870-882.

17. Zammit PS (2006) Pax7 and myogenic progression in skeletal muscle satellite cells. J Cell Sci; 119(9):1824-1832.

18. Kuang S, Charge SB, Seale P, Huh M and Rudnicki MA (2006) Distinct roles for $\mathrm{Pax} 7$ and $\mathrm{Pax} 3$ in adult regenerative myogenesis. J Cell Biol; 172(1):103-113.

19. Relaix F (2006) Pax3 and Pax7 have distinct and overlapping functions in adult muscle progenitor cells. J Cell Biol; 172(1):91-102.

20. Peault, B., Rudnicki, M., Torrente, Y., Cossu, G., Tremblay, J. P., Partridge, T.,\& Huard, J.(2007). Stem and progenitor cells in skeletal muscle development, maintenance, and therapy. Mol Ther. 15(5):867-877.

21. Zierath JR and Hawley (2004) Skeletal Muscle Fiber Type: Influence on Contractile and Metabolic Properties. JA PLOS Biol; 22:29-32.

22. Huang YC, Dennis RG and Baar K (2006) Cultured slow vs. fast skeletal muscle cells differ in physiology and responsiveness to stimulation. Am J Physiol Cell Physiol; 291: C11-C17.

23. Kalhovde JM, Jerkovic R, Sefland I, Cordonnier C, Calabria E, Schiaffino S and Lomo T (2005) "Fast" and "slow" muscle fibers in hind limb muscles of adult rats regenerate from intrinsically different satellite cells. $J$ Physiol; 562: 847-857.

24. Kierszenbaum L K and Loura T (2011) Histology and cell biology with introduction to pathology .3rd ed, Licensing Agency Elsevier, Philadelphia, USA, P: 203-216.

25. Nahirney PC and Ovalle W (2011) Netter's Essential Histology.2rd ed, Elsevier Health Science Churchill living stone, Philadelphia, USA. P: 71-100.

26. Grogan BF and Hsu JR (2011) Volumetric muscle loss. J Am Acad Orthop Surg; 19 (1): 35-37.

27. Dhawan J and Rando TA (2005) Stem cells in postnatal myogenesis: molecular mechanisms of satellite cell quiescence, activation and replenishment. J Cell Biol; 15(12):666-673.

28. Price FD, Kuroda K and Rudnicki MA (2007) Stem cell based therapies to treat muscular dystrophy. Biochim Biophys Acta; 1772(2):272-283.

29. Leshem Y, Spicer DB, Gal-Levi R and Halevy O (2000) Hepatocyte growth factor (HGF) inhibits skeletal muscle cell differentiation: a role for the bHLH protein twist and the cdk inhibitor. J Cell Physiol; 184: 101-109.

30. Musaro A (2005) Growth factor enhancement of muscle regeneration: a central role of IGF-1. Arch Ital Biol; 143(3):243248.

31. Wozniak AC and Anderson JE (2007) Nitric oxide-dependence of satellite stem cell activation and quiescence on normal skeletal muscle fibers. Dev Dyn; 236(1):240-250.

32. Rossi CA, Pozzobon M, Ditadi A, Archacka K and Gastaldello A (2010) Clonal Characterization of Rat Muscle Satellite Cells: Proliferation, Metabolism and Differentiation Define an Intrinsic Heterogeneity. PLoS ONE journal; 5(1):8523-8524.

33. Collins CA, Olsen I, Zammit PS, Heslop L, Petrie A, Partridge TA and Morgan JE (2005) Stem cell function, self-renewal, and behavioral heterogeneity of cells from the adult muscle satellite cell niche. Stem Cells; 122: 289-301.

34. Sacco A, Doyonnas R, Kraft P, Vitorovic S and Blau HM (2008) Self-renewal and expansion of single transplanted muscle stem cells. Nature; 456: 502-506.

35. Rocheteau P, Gayraud-Morel B, Siegl-Cachedenier I, Blasco M A and Tajbakhsh S (2012) A subpopulation of adult skeletal muscle stem cells retains all template DNA strands after cell division. Cell; 148: 112-125.

36. Asakura A, Komaki M and Rudnicki M (2001) Muscle satellite cells are multipotential stem cells that exhibit myogenic, osteogenic, and adipogenic differentiation. $J$ histochem and cytochem; 68: 245-253.

37. Day K, Shefer G, Shearer A and Yablonka-Reuveni Z (2010) The depletion of skeletal muscle satellite cells with age is concomitant with reduced capacity of single progenitors to produce reserve progeny. Dev Biol: 340: 330-343.

38. Starkey JD, Yamamoto M, Yamamoto S and Goldhamer D J (2011) Skeletal muscle satellite cells are committed to myogenesis and do not spontaneously adopt nonmyogenic fates. J Histochem Cytochem; 59: 33-46. 
39. Ono Y, Calhabeu F, Morgan J E, Katagiri T, Amthor H and Zammit P S (2011) BMP signalling permits population expansion by preventing premature myogenic differentiation in muscle satellite cells. Cell Death Differ; 18: 222-234.

40. Lounev VY, Ramachandran R, Wosczyna MN, Yamamoto M, Maidment AD, Shore EM, Glaser DL, Goldhamer D J and Kaplan FS (2009): Identification of progenitor cells that contribute to heterotopic skeletogenesis. J Bone Joint Surg Am; 91: 652-663.

41. Ono Y, Masuda S, Nam H S, Benezra R, Miyagoe-Suzuki Y and Takeda S (2012) Slow-dividing satellite cells retain long-term self-renewal ability in adult muscle. J Cell Sci; 125: 1309-1317.

42. Tamaki T, Akatsuka A, Ando K, Nakamura Y and Matsuzawa $\mathrm{H}$ (2002) Identification of myogenic-endothelial progenitor cells in the interstitial spaces of skeletal muscle. J Cell Biol; 157: 571577.

43. Cossu G and Bianco P (2003) Mesoangioblasts-vascular progenitors for extravascular mesodermal tissues. Curr Opin Genet Dev; 13: 537-542.

44. Uezumi A, Ojima K, Fukada S, Ikemoto M and Masuda S (2006) Functional heteogeneity of side population cells in skeletal muscle. Biochem Biophys Res Commun. 341: 864-873.

45. Benchaouir R, Meregalli M, Farini A, D'Antona G and Belicchi M (2007) Restoration of human dystrophin following transplantation of exon-skipping-engineered DMD patient stem cells into dystrophic mice. Stem Cell; 1: 646-657.

46. Zheng B, Cao B and Crisan M (2007) Prospective identification of myogenic endothelial cells in human skeletal muscle. Nat Biotechnol; 25(9):1025-1034.

47. Chen CW, Montelatici E, Crisan M, Corselli M and Huard J (2009) Perivascular multi-lineage progenitor cells in human organs: regenerative units, cytokine sources or both? Cytokine Growth Factor Rev. NEJM; 20: 429-434.

48. Qu-Petersen Z, Deasy B and Jankowski R (2002) Identification of a novel population of muscle stem cells in mice: potential for muscle regeneration. J Cell Biol; 157(5):851-864.

49. Young HE (1999) Human pluripotent and progenitor cells display cell surface cluster differentiation markers CD10, CD13, CD56 and MHC class-I. Proc Soc Exp Biol Med; 221: 63-71.

50. Pittenger (1999) Multilineage potential of adult human mesenchymal stem cells. Science; 284: 143-147.

51. Beauchamp JR, Morgan JE, Pagel CN and Partridge TA (1999) Dynamics of myoblast transplantation reveal a discrete minority of precursors with stem cell-like properties as the myogenic source. J Cell Biol; 144: 1113-1122.

52. Macintosh BR, Gardiner PF and McComas AJ (2006) Muscle Architecture and Muscle Fiber Anatomy.2nd ed. Elsevier Health Science Churchill living stone, Champaign, USA, P; 3-21.

53. Owens BD, Kragh JF and Wenke JC (2008) Combat wounds in operation Iraqi Freedom and operation Enduring Freedom. $J$ Trauma; 64:295-299.

54. Lew TA, Walker JA and Wenke JC (2010): Characterization of cranio-maxillo-facial battle injuries sustained by United States service members in the current conflicts of Iraq and Afghanistan. J Oral Maxillofac Surg; 68:3-7.

55. Hill M, Wernig A and Goldspink G (2003) Muscle satellite (stem) cell activation during local tissue injury and repair. $J$ Cell Mol Med; 115(45): 89-108.

56. Kin S (2007) Regeneration of skeletal muscle using in situ tissue engineering on an acellular collagen sponge scaffold in a rabbit model. ASAIO J; 53 (12): 506-514.

57. Charley G and Johnny H (2006) Management of Skeletal Muscle Injuries in Military Personnel. J Cell Biol; 14: 74-82.
58. Doyonnas R, LaBarge MA, Sacco A, Charlton C, and Blau HM (2004) Hematopoietic contribution to skeletal muscle regeneration by myelomonocytic precursors. Proc Natl Acad Sci USA; 101: 13507-13512.

59. Mourkioti F and Rosenthal N (2005) IGF-1, inflammation and stem cells: interactions during muscle regeneration. Trends Immunol; 26: 535-542.

60. Prisk V and Huard J (2003) Muscle injuries and repair: the role of prostaglandins and inflammation. Histol Histopathol; 18: 1243-1256.

61. Bodine SC, Latres E, Baumhueter S, Lai VK, Nunez L, Clarke BA, Poueymirou WT, Panaro FJ, Na E, Dharmarajan K, Pan ZQ, Valenzuela DM, DeChiara TM, Stitt TN, Yancopoulos GD and Glass DJ (2001): Identification of ubiquitin ligases required for skeletal muscle atrophy. Science; 294: 1704-1708.

62. Li YP (2003) TNF-alpha is a mitogen in skeletal muscle. Am J Physiol Cell Physiol; 285: C370-376.

63. Sorichter S, Mair J, Koller A, Muller E, Kremser C, Judmaier W, Haid C, Calzolari C and Puschendorf B (2001) Creatine kinase, myosin heavy chains and magnetic resonance imaging after eccentric exercise. J Sports Sci; 19: 687-691.

64. McClung JM, Davis JM and Carson JA (2007) Ovarian hormone status and skeletal muscle inflammation during recovery from disuse in rats. Exp Physiol; 92: 219-232.

65. Menetrey J, Kasemkijwattana C, Day CS, Bosch P, Vogt M, Fu FH, Moreland MS and Huard J (2000) Growth factors improve muscle healing in vivo. J Bone Joint Surg Br; 82: 131-137.

66. Summan M, Warren GL and Mercer RR (2006) Macrophages and skeletal muscle regeneration: a clodronate-containing liposome depletion study. Am J Physiol Regul Integr Comp Physiol; 290(6): R1488-495.

67. Shen W, Prisk V and Li Y (2006) Inhibited skeletal muscle healing in cyclooxygenase-2gene-deficient mice. J Appl Physiol; 101(4):1215-1221.

68. Gadient RA and Patterson PH (1999) Leukemia inhibitory factor, Interleukin 6, and other cytokines using the GP130 transducing receptor: roles in inflammation and injury. Stem Cells; 17: 127137.

69. Luo G, Hershko DD, Robb BW, Wray CJ and Hasselgren PO (2003) IL-1beta stimulates IL-6 production in cultured skeletal muscle cells through activation of MAP kinase signaling pathway and NF-kappa B. Am J Physiol Regul Integr Comp Physiol; 284: 1249-1254.

70. Frost RA, Nystrom GJ and Lang CH (2004) Epinephrine stimulates IL-6 expression in skeletal muscle and $\mathrm{C} 2 \mathrm{C} 12$ myoblasts: role of c-Jun NH2-terminal kinase and histone deacetylase activity. Am J Physiol Endocrinol Metab; 286: 809817.

71. Miller KJ, Thaloor D, Matteson S and Pavlath GK (2000) Hepatocyte growth factor affects satellite cell activation and differentiation in regenerating skeletal muscle. Am J Physiol Cell Physiol; 278: 174-181.

72. Dusterhoft S, and Pette D (1999) Evidence that acidic fibroblast growth factor promotes maturation of rat satellite cell-derived myotubes in vitro. Differentiation; 65: 161-169.

73. Kastner S, Elias MC, Rivera AJ and Yablonka-Reuveni Z (2000) Gene expression patterns of the fibroblast growth factors and their receptors during myogenesis of rat satellite cells. $J$ Histochem Cytochem; 48: 1079-1096.

74. Hayashi S, Aso H, Watanabe K, Nara H, Rose MT, Ohwada S and Yamaguchi T (2004) Sequence of IGF-1, IGF-1l, and HGF expression in regenerating skeletal muscle. Histochem Cell Biol; 122:427-34. 
75. Lawlor MA and Rotwein P (2000) Insulin-like growth factormediated muscle cell survival: central roles for Akt and cyclindependent kinase inhibitor p21. Mol Cell Biol; 20: 8983-8995.

76. Musaro A, Cristina G, Giovanna B, Dobrowolny G, Laura P, Linda C (2004) Stem cell-mediated muscle regeneration is enhancedby local isoform of insulin-like growth factor 1 . The National Academy of Sciences of the USA; 101 (5):1206-1210.

77. Collins RA and Grounds MD (2001) The role of tumor necrosis factor-alpha (TNF-alpha) in skeletal muscle regeneration. Studies in TNF-alpha (-/-) and TNF-alpha (-/-)/LT-alpha (-/) mice. J Histochem Cytochem; 49: 989-1001.

78. Warren GL, Hulderman T, Jensen N, McKinstry M, Mishra M, Luster MI and Simeonova PP (2002) Physiological role of tumor necrosis factor alpha in traumatic muscle injury. FASEB $J ; 16$ : 1630-1632.

79. Li Y and Huard J (2001) Muscle injury and repair. Curr Opin Orthop; 12: 409-415.

80. Blaveri K, Heslop L, Yu DS, Rosenblatt JD, Gross JG, Partridge TA, and Morgan JE (1999) Patterns of repair of dystrophic mouse muscle: studies on isolated fibers. Vis. Sci; 216: 244-256.

81. Zammit PS (2002) Kinetics of myoblast proliferation show that resident satellite cells are competent to fully regenerate skeletal muscle fibers. Exp Cell Res; 281(1):39-49.

82. Zammit PS (2004) Muscle satellite cells adopt divergent fates: a mechanism for self-renewal? J Cell Biol; 166(3):347-357.

83. Li Y, Foster W and Deasy BM (2004) Transforming growth factor-beta1 induces the differentiation of myogenic cells into fibrotic cells in injured skeletal muscle, a keye vent in muscle fibrogenesis. Am J Pathol; 164(3):1007-1019.

84. Casar JC, Cabello-Verrugio C, Olguin H, Aldunate R, Inestrosa NC and Brandan E (2004) Heparan sulfate proteoglycans are increased during skeletal muscle re- generation: requirement of syndecan-3 for successful fiber formation. J Cell Sci; 117: 7384.

85. Shen W, Li Y and Tang Y (2005) cyclooxygenase-2-specific inhibitor, delays skeletal muscle healing by decreasing regeneration and promoting fibrosis. AmJ Pathol; 167(4):11051117.

86. Kaariainen M, Jarvinen $\mathrm{T}$ and Jarvinen M (2000) Relation between myofibers and connective tissue during muscle injury repair. Scand J Med Sci Sports; 10(6):332-337.

87. Foster W, Li Y and Usas A (2003): Gamma interferon as an antifibrosis agent in skeletal muscle. J Orthop Res; 21(5):798804.

88. Nozaki M, Yong Li and Zhu IL (2008) Improved muscle healing after contusion injury by the inhibitory effect of suramin on myostatin, a negative regulator of muscle growth. American Journal of Sports Medicine; 36(12): 2354-2362.

89. Chan Y S, Li Y, Foster W, Fu F H and Huard J (2005) The use of suramin, an antifibrotic agent to improve muscle recovery after strain injury. American Journal of Sports Medicine; 33(1):43-51.

90. Fukushima K, Badlani N, Usas A, Riano F, Fu FH and Huard J (2001) The use of an antifibrosis agent to improve muscle recovery after laceration. American Journal of Sports Medicine; 29(4):394-402.

91. Quintero A, Wright V and Fu F (2009) Stem cells for the treatment of skeletal muscle injury. Clinics in Sports Medicine; 28: 1-11.

92. Osses N and Brandan E (2002) ECM is required for skeletal muscle differentiation independently of muscle regulatory factor expression. Am J Physiol Cell Physiol; 282(48): 383-388.

93. Velleman S (2002): Role of the extracellular matrix in muscle growth and development. J Anim Sci; 80: 8-13.
94. Carmeli E, Moas M, Reznick AZ and Coleman R (2004) Matrix metalloproteinases and skeletal muscle: a brief review. Muscle Nerve Biophys; 29: 191-197.

95. Goetsch SC, Hawke TJ, Gallardo TD, Richardson JA and Garry DJ (2003) Transcriptional profiling and regulation of the extracellular matrix during muscle regeneration. Physiol Genomics; 14: 261-271.

96. El Fahime E, Torrente Y, Caron NJ, Bresolin MD and Tremblay JP (2000) In vivo migration of transplanted myoblasts requires matrix metalloproteinase activity. Exp Cell Res; 258: 279-287.

97. Mannello F, Tonti GA, Bagnara GP and Papa S (2006) Role and function of matrix metalloproteinases in the differentiation and biological characterization of mesenchymal stem cells. Stem Cells; 24: 475-481.

98. Myohanen H, and Vaheri A (2004) Regulation and interactions in the activation of cell-associated plasminogen. Cell Mol Life Sci; 61: 2840-2858.

99. Stepanova VV and Tkachuk VA (2002) Urokinase as a multidomain protein and polyfunctional cell regulator. $J$ Cell Biol; 67: 109-118.

100. Suelves M, Lluis F, Ruiz V, Nebreda AR and Munoz-Canoves P (2004) Phosphorylation of MRF4 transactivation domain by $\mathrm{p} 38$ mediates repression of specific myogenic genes. EMBO J;23: 365-375.

101. Abofila, M. T., Azab, A. E., Al Shebani, A. M., and Bshena, A. N. (2021). Stem Cells: Insights into Niche, Classification, Identification, Characterization, Mechanisms of Regeneration by Using Stem Cells, and Applications in Joint Disease Remedy. J, Biotech. and Bioprocessing; 2(1): 2766-2314.

102. Suelves M, Lluis F, Ruiz V, Nebreda AR and Munoz-Canoves P. (2004). Phosphorylation of MRF4 transactivation domain by p38 mediates repression of specific myogenic genes. EMBO J; 23: 365-375.

103. Vekris MD (2008) Restoration of elbow function in severe brachial plexus paralysis via muscle transfers. Am J; 39 (3):1525.

104. Martins, I. J. (2017). Single gene inactivation with implications to diabetes and multiple organ dysfunction syndrome. J Clin Epigenet; 3(24): 2472-1158.

105. Martins, I. J. (2016). Anti-aging genes improve appetite regulation and reverse cell senescence and apoptosis in global populations. Advan Aging Res; 5(1): 9-26.

106. Martins, I. J. (2018). Increased risk for obesity and diabetes with neurodegeneration in developing countries. J Mol Genet Med S1:001.

107. Martins I. (2016). Early diagnosis of neuron mitochondrial dysfunction may reverse global metabolic and neurodegenerative disease. GJMR; 2: 1-8.

108. Martins IJ. (2017). Drug-drug interactions with relevance to drug induced mitochondrial toxicity and accelerated global chronic diseases. ECPT;3(1):18-21.

109. Hall, J. A., Dominy, J. E., Lee, Y., and Puigserver, P. (2013). The sirtuin family's role in aging and age-associated pathologies. J Clinical Invest.; 123(3), 973-979.

110. Colak, Y., Yesil, A., Mutlu, H. H., Caklili, O. T., Ulasoglu, C., Senates, E., and Tuncer, I. (2014). A potential treatment of nonalcoholic fatty liver disease with SIRT1 activators. J Gastrointestin Liver Dis; 23(3), 311-319.

111. Dixon, J., Lane, K., MacPhee, I., \& Philips, B. (2014). Xenobiotic metabolism: the effect of acute kidney injury on non-renal drug clearance and hepatic drug metabolism. Inter J Mol Sci; 15(2), 2538-2553.

112. Conti, V., Corbi, G., Manzo, V., Pelaia, G., Filippelli, A., and Vatrella, A. (2015). Sirtuin 1 and aging theory for chronic 
obstructive pulmonary disease. Analyt Cell Pathol; 2015: 897327.

113. Guan, Y., and Hao, C. M. (2015). SIRT1 and kidney function. Kidney Diseases; 1(4): 258-265.

114. Mariani, S., Fiore, D., Basciani, S., Persichetti, A., Contini, S., Lubrano, C., and Gnessi, L. (2015). Plasma levels of SIRT1 associate with non-alcoholic fatty liver disease in obese patients. Endocrine; 49(3): 711-716.

115. Matsushima, S. and J. Sadoshima (2015). The role of sirtuins in cardiac disease. Amer J Physiol-Heart Circ Physiol; 309(9): H1375-H1389.

116. You, M., Jogasuria, A., Taylor, C., and Wu, J. (2015). Sirtuin 1 signaling and alcoholic fatty liver disease. Hepatobil Surg Nutr; 4(2): 88.

117. Nassir, F. and J. A. Ibdah (2016). Sirtuins and nonalcoholic fatty liver disease. World J Gastroenterol; 22(46): 10084.

118. Hui, X., Zhang, M., Gu, P., Li, K., Gao, Y., Wu, D., and Xu, A. (2017). Adipocyte SIRT 1 controls systemic insulin sensitivity by modulating macrophages in adipose tissue. EMBO Reports; 18(4):645-657.

119. Yanagisawa, S., Papaioannou, A., Papaporfyriou, A., Baker, J., Vuppusetty, C., Loukides, S., and Ito, K. (2017). Decreased serum sirtuin-1 in chronic obstructive pulmonary disease. Chest: 1-39. doi: 10.1016/j.chest.2017.05.004.

120. Martins, I. (2017). Nutrition therapy regulates caffeine metabolism with relevance to NAFLD and induction of type 3 diabetes. J Diabetes Metab Disord; 4(1): 1-9.

121. Cantó, C. and J. Auwerx (2009). Caloric restriction, SIRT1 and longevity. Trends Endocrinol Metab; 20(7): 325-331.

122. Pardo, P. S. and A. M. Boriek (2011). The physiological roles of Sirt1 in skeletal muscle. Aging (Albany NY); 3(4): 430.

123. del Carmen Ortuño-Costela, M., García-López, M., Cerrada, V., and Gallardo, M. E. (2019). iPSC s: A powerful tool for skeletal muscle tissue engineering. J Cell Mole Med; 23(6): 3784-3794.

124. Costantini, M., Testa, S., Fornetti, E., Fuoco, C., Sanchez Riera, C., Nie, M., and Gargioli, C. (2021). Biofabricating murine and human myo-substitutes for rapid volumetric muscle loss restoration. EMBO Mole Med; 13(3): e12778. 